\title{
PEMODELAN REAKSI SUHU UDARA TERHADAP PENYINARAN CAHAYA MATAHARI DALAM HUTAN BAKAU
}

\section{Modeling Air Temperature Reaction on Sunlight Lighting in Mangrove Forests}

\author{
Mario Nikolaus Dalengkade* \\ Program Studi Matematika, Fakultas Ilmu Alam dan Tenologi Rekayasa, Universitas Halmahera \\ Jln. Wari Raya, Tobelo, Halmahera Utara, Maluku Utara, Indonesia \\ e-mail: mariodalengkade@gmail.com \\ Corresponding author*
}

\begin{abstract}
Abstrak
Intensitas cahaya matahari dan suhu udara merupakan parameter iklim mikro yang berperan penting dalam proses biologis hutan bakau. Untuk mengetahui profil harian suhu udara yang di kontrol oleh intensitas cahaya matahari menggunakan fungsi Fourier yakni $f(t)=T_{0} \sum_{m=0}^{N / 2} a_{m} \cos \omega_{m} t+$ $b_{m} \sin \omega_{m} t$. Hasil penelitian menunjukan fluaktuasi kuat penerangan dan suhu udara pada posisi 1 (4 meter di luar hutan bakau) dan posisi 3 (tepi hutan bakau) lebih tinggi. Sedangkan posisi 9 (32 meter dalam hutan bakau) lebih rendah, hal ini disebabkan oleh hutan bakau mampu mereduksi kuat penerangan. Pengujian korelasi silang antara kuat penerangan dengan suhu udara menunjukan timelag dari posisi posisi 1 posisi 3 yakni 1.0 jam. Sedangkan posisi 3 ke posisi 9 ialah 1.3 jam, hal ini memperlihatkan bahwa difusi termal dikendalikan oleh arah horisontal. Dari perhitungan variabel iklim mikro dan pengujian korelasi silangnya membuktikan bahwa ekosistem bakau mampu menjaga keseimbangan iklim mikro daerah pesisir.
\end{abstract}

Kata Kunci : Hutan bakau, fungsi Fourier, kuat penerangan, suhu udara.

\begin{abstract}
The intensity of sunlight and air temperature are a parameter of microclimate which plays an important role in the biological processes of mangroves. To find out the daily profile of air temperature which is controlled by the intensity of sunlight using Fourier functions namely $f(t)=T_{0} \sum_{m=0}^{N / 2} a_{m} \cos \omega_{m} t+$ $b_{m} \sin \omega_{m} t$. The results of the study showed fluorescence of lighting strength and air temperature at position 1 (4 meters outside mangrove forest) and position 3 (edge of mangrove forest) was higher. Whereas position 9 (32 meters in mangrove forest) is lower, this is caused by mangrove forests being able to reduce lighting power. Testing of cross correlation between the strength of illumination and air temperature shows the distance from position 1 position 3 which is 1.0 hours. While position 3 to position 9 is 1.3 hours, this shows that thermal diffusion is controlled by the horizontal direction. From the calculation of micro climate variables and cross correlation testing, it proves that mangrove ecosystems are able to maintain the balance of the microclimate of coastal areas.
\end{abstract}

Keywords : Mangrove forest, Fourier function, lighting power, air temperature. 


\section{PENDAHULUAN}

Hutan bakau yakni mengacu pada ekosistem tumbuhan khas daerah tropis dan sub-tropis antara lain Rhizophora, Bruguiera, maupun Nypa yang selalu tergenang air pasang-surut serta tahan akan perubahan iklim [1,18]. Bagi hutan bakau $\mathrm{CO}_{2}$ (karbon dioksida) sangat penting dalam proses fisiologis [1], tapi akumulasi $\mathrm{CO}_{2}$ yang berlebihan menyebabkan efek rumah kaca menjadi ancaman bagi bakau [2]. Ancaman yang dimaksud adalah perombakan iklim mikro seperti daya tembus cahaya matahari, daya tembus angin, presipitasi, suhu udara, dan kelembaban udara [4]. A. Mitra [1] menyatakan kegiatan seperti pengeboran minyak, gas alam, dan batu bara menyebabkan pelepasan $\mathrm{CO}_{2}$ di atmosfer meningkat mencapai $30 \%$. Hal tersebut berimbas pada peningkatan suhu sebesar $1-2^{0} \mathrm{~F}$ (farenheit), sehingga berpotensi mempengaruhi iklim secara global. Selain itu, akibat kegiatan di atas menurut [7] sejak 1880 terjadi peningkatan 0.6-0.8 ${ }^{0} \mathrm{C}$ di daerah industri, dan diproyeksikan sampai tahun 2100 mencapai $2-6{ }^{\circ} \mathrm{C}$. Peningkatan $\mathrm{CO}_{2}$ yang terjadi dapat menyebabkan terganggunya iklim mikro [6,13]. Baru-baru ini penelitian [4] menyatakan sepanjang transek pengukuran di padang rumput untuk variabel kecepatan angin $1.9-1 \mathrm{~m} \mathrm{~s}^{-1}$, suhu udara $10-7{ }^{\circ} \mathrm{C}$, defisit tekanan udara $4.8-4 \mathrm{mB}$, dan suhu tanah $9-11{ }^{0} \mathrm{C}$ sampai kebatas ekosistem hutan. Sedangkan ekosistem hutan pengukuran sepanjang transek variabel kecepatan angin $1.1-0.1 \mathrm{~m} \mathrm{~s}^{-1}$, suhu udara $7-0.1{ }^{\circ} \mathrm{C}$, defisit tekanan udara $3-0.5 \mathrm{mB}$, dan suhu tanah $8-6{ }^{\circ} \mathrm{C}$. Temuan [9] yakni transek pengukuran sepanjang $400 \mathrm{~m}$ terdiri dari $200 \mathrm{ke}$ arah padang rumput dan $200 \mathrm{~m}$ ke arah hutan memperlihatkan defisit iklim mikro $20 \%-5 \%$. Berdasarkan hasil penelitian tersebut, maka ekosistem hutan mampu mereduksi perubahan iklim akibat peningkatan $\mathrm{CO}_{2}$. Peneliti sebelumnya $[1,7,13]$ menyatakan hutan bakau merupakan salah satu solusi untuk mereduksi perubahan iklim. Karena diyakini bahwa $\mathrm{CO}_{2}$ yang berada di atmosfer mampu diikat oleh senyawa-senyawa tertentu air laut (melalui proses gaya tarik antar partikel udara) di ikuti dengan pengikatan kembali oleh hutan bakau.

Variabel-variabel iklim mikro seperti yang di laporkan diatas semuanya merupakan deret waktu. Untuk menganalisis iklim mikro, menurut $[5,6,11,12,14]$ dapat menggunakan analisis Fourier atau disebut analisis harmonik. Jika deret Fourier dinyatakan dengan fungsi periodik persamaan 1:

$$
f(t)=F(t+T) \text {. }
$$

Dimana $T$ adalah nilai terkecil dari periode yang mungkin dimiliki oleh $f(t)$. Asalkan $f(t)$ memenuhi syarat-syarat Dirichlet sebagai berikut:

1. $f(t)$ bernilai tunggal.

2. $f(t)$ terintegrasi secara mutlak, berarti $\int_{t_{0}}^{t_{0}+T}|f(t)| d t$ berhingga untuk setiap pemilihan $\mathrm{t}_{0}$.

3. $f(t)$ memiliki diskuntinuitas yang terbatas jumlahnya dalam setiap periode.

4. $f(t)$ mempunyai nilai ekstrim yang terbatas banyaknya dalam $t$ tiap periode.

Maka $f(t)$ dapat dijabarkan kedalam deret suku-suku harmonik sinus/kosinus persamaan 2:

$$
f(t)=\frac{a_{0}}{2}+\sum_{n=1}^{\infty}\left(a_{n} \operatorname{Cos} n \omega t+b_{n} \operatorname{Sin} n \omega t\right) . .
$$

Dimana $\omega$ merupakan konstanta matematik (bermakna fisis) yang memenuhi definisi persamaan 3:

$$
\omega=\frac{2 \pi}{T}
$$

Apabila $t$ yakni variabel waktu maka $\omega$ ialah parameter frekuensi bernilai waktu. Pada persamaan 2 yakni $a_{n}$ dan $b_{n}$ dinamakan koefisien Fourier maka untuk penentuan koefisien tersebut diberikan oleh persamaan 4a serta 4b:

$$
\begin{aligned}
& a_{n}=\frac{2}{T} \int_{t_{0}}^{t_{0}+T} f(t) \operatorname{Cos} n \omega t \\
& b_{n}=\frac{2}{T} \int_{t_{0}}^{t_{0}+T} f(t) \operatorname{Sin} n \omega t
\end{aligned}
$$

Menelaah kembali mengenai varibel iklim mikro yang memenuhi syarat-syarat Dirichlet, sehingga penelitian mengenai iklim mikro di hutan bakau sangat penting karena berfungsi sebagai studi lapangan, pemodelan teoritik, pengambilan kebijakan manajemen sumber daya, dan pemantauan kondisis ekosistem bakau [8]. 


\section{METODE PENELITIAN}

Pelaksanaan penelitian iklim mikro, yakni di hutan bakau Ratatotok Timur Kecamatan Ratatotok Kabupaten Minahasa Tenggara. Pemodelan iklim mikro kuat penerangan/intensitas cahaya matahari (I) dan suhu udara (T) menggunakan fungsi Fourier, mengacu pada peneliti sebelumnya [3, 4]. Sehingga pemodelan iklim mikro untuk setiap posisi pengukuran menghasilkan fungsi semata. Fungsi Fourier yang digunakan untuk memodelkan variabel iklim mikro adalah:

$$
f(t)=T_{0} \sum_{m=0}^{\frac{N}{2}} a_{m} \cos \omega_{m} t+b_{m} \sin \omega_{m} \ldots \ldots \ldots \ldots \ldots \ldots
$$

Dimana:

$$
\begin{aligned}
& \omega_{m}=\frac{2 \pi m}{N} \\
& a_{m}=\frac{2}{N} \sum_{t=0}^{N-1} f(t) \cos \omega_{m} t \\
& b_{m}=\frac{2}{N} \sum_{t=0}^{N-1} f(t) \sin \omega_{m} t
\end{aligned}
$$

m yakni cacah suku deret Fourier dan $N$ adalah banyaknya data (pasangan data variabel bebas waktu $(t)$ dan variabel terikat suhu udara $(T), f(t)$ adalah suhu udara hasil pengukuran dilapangan, $a_{m}$ dan $b_{m}$ adalah koefisien Fourier. Pengukuran setiap variabel (I dan T) selama 25 jam dengan interval waktu 1 jam, sehingga menghasilkan $N=25$. Pengukuran setiap variabel dimulai dari jam 06.00-18.00, sehingga diperoleh data $N=13$. Banyak harmonik yakni N/2, maka untuk 25 data pengamatan, nilai $m$ yakni: $1,2,3, \ldots \ldots, 12$. Untuk jumlah $\mathrm{N}=13$, data pengamatan $\mathrm{m}=1,2,3, \ldots \ldots, 6$. Prosedur pemodelan setiap varibel iklim mikro yakni:

1. Menentukan harga koefisien $a_{m}$ dan $b_{m}$, menggunakan persaman (7) dan persamaan (8).

2. Menentukan koefisien $c_{m}{ }^{2}=a_{m}{ }^{2}+b_{m}{ }^{2}$.

3. Menentukan sumbangan keragaman: $s_{m}=\left(c_{m}^{2} /(2 . \sigma)\right) * 100$

4. Sinkronisai data antar posisi pengukuran. Sinkronisasi data dilakukan karena pengukuran tidak serempak, tapi berpindah dari posisi satu ke posisi lainnya sepanjang transek. Sinkronisasi data ini dilakukan dengan memasukan data selisih waktu pengukuran dari posisi satu ke posisi selanjutnya, ke dalam fungsi berikutnya. Sinkronisasi ini tidak mengubah fungsi tapi memberikan yang harga baru untuk setiap posisi.

5. Uji korelasi silang (cross-correlation). Uji korelasi silang ditunjukan guna menghitung timelag perubahan antara variabel kuat penerang terhadap variabel suhu udara. Persamaan yang digunakan untuk menentukan korelasi silang yakni $[17,14]$ :

$$
\left.r=\sum_{i}^{n}\{(x(i)-m x)) \cdot(y(i-d)-m y)\right\} / \operatorname{sqr}\left\{\sum _ { i } ^ { n } ( x ( ( i ) - m x ) ^ { 2 } \} \cdot \operatorname { s q r } \left\{\sum_{i}^{n}\left(y((i-d)-m y)^{2}\right\} \ldots\right.\right.
$$

Dimana: $\quad r=$ koefisien korelasi,

$n=$ banyaknya pasangan data variabel bebas (x) dan variabel terikat $(\mathrm{y})$,

$m=$ konstanta,

$i=$ cacah data,

$d=$ timelag antar variabel $x$ serta $y$.

Untuk menentukan lag antara $x$ dan $y$ yakni dari nilai maksimal $r$. Proses penentuan lag yakni menggeser salah satu fungsi (misalnya $y$ ) terhadap $x$ (proses iterasi). Pergeseran ini dilakukan dengan cara mengiterasi 
$d$ dengan interval tertentu. Nilai $d$ awal dapat dipilih sama dengan nol atau menggunakan nilai tertentu jika terdapat acuan lag kedua fungsi. Penggeseran diteruskan selama $r$ bertambah dan dihentikan ketika mencapai nilai tertinggi. Lag kedua fungsi adalah nilai $d$ ketika nilai $r$ maksimal.

\section{HASIL DAN PEMBAHASAN}

\subsection{Deskripsi Transek Pengukuran}

Pengukuran untuk setiap variabel selama 25 jam, dengan titik pengambilan data di tunjukan pada Tabel 1, berikut:

Tabel 1. Koordinat transek pengukuran lokasi Ratatotok Timur

\begin{tabular}{|c|c|c|c|c|c|c|c|c|}
\hline \multirow{3}{*}{ 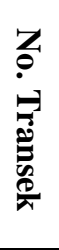 } & \multicolumn{4}{|c|}{ Posisi (koordinat) titik ujung transek } & \multirow{3}{*}{ 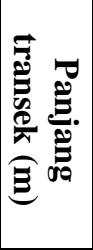 } & \multirow{2}{*}{\multicolumn{3}{|c|}{ Jarak ke batas ekosistem (m) }} \\
\hline & \multicolumn{2}{|c|}{ Luar hutan mangrove } & \multicolumn{2}{|c|}{ Dalam hutan mangrove } & & & & \\
\hline & Lintang & Bujur & Lintang & Bujur & & $\begin{array}{c}\text { Arah } \\
\text { transek }\end{array}$ & Kiri & Kanan \\
\hline 1. & $0^{0} 51^{\prime} 20.95^{\prime \prime}$ & $124^{0} 42^{\prime} 24.28$ & $0^{0} 51 ' 20.97 \prime$ & $124^{0} 42^{\prime} 23.66^{\prime \prime}$ & 36 & 746 & 764 & 1500 \\
\hline
\end{tabular}

Topografi transek pengambilan data bervariasi, karena bagian tepi berbatasan dengan laut lebih rendah daripada bagian tengah. Sehingga menyebabkan penggenangan air laut tidak merata. Jenis yang tumbuh di area transek tersebut yakni Rhizophora dengan tutupan kanopi 85-92\%.

\subsection{Pemodelan Temporal Kuat Penerangan dan Suhu Udara}

Seperti yang tertuang di metode penelitian, didapatkan luaran analisis untuk setiap posisi dari kedua variabel (Tabel 2), tapi dalam tulisan ini hanya memaparkan 3 posisi yakni posisi 1 (4 meter) di luar hutan bakau, posisi 3 di tepi hutan bakau, dan posisi 9 (32 meter) dalam hutan bakau.

Tabel 2. Luaran fungsi Fourier kuat penerangan dan suhu udara untuk 3 posisi yang berbeda.

\begin{tabular}{|c|c|c|c|c|c|c|}
\hline \multicolumn{7}{|c|}{ Kuat Penerangan } \\
\hline \multirow{2}{*}{ Posisi } & \multirow{2}{*}{ Jum. Data } & \multirow{2}{*}{ Rerata } & \multirow{2}{*}{ Varian } & \multicolumn{2}{|c|}{ Koefisien Fourier } & \multirow{2}{*}{ Sum. Keragaman } \\
\hline & & & & $\mathbf{A j}$ & $\mathbf{B j}$ & \\
\hline 1. & 427.30 & 32.869 & 391.759 & -26.145 & -8.713 & 96.931 \\
\hline 3. & 420.10 & 32.315 & 388.123 & $\begin{array}{r}-26.001 \\
-3.602\end{array}$ & $\begin{array}{l}-8.748 \\
-0.723\end{array}$ & 96.953 \\
\hline 9. & 179.70 & 13.823 & 77.156 & $\begin{array}{r}-11.660 \\
-1.862 \\
-0.750\end{array}$ & $\begin{array}{l}-3.107 \\
-0.691 \\
-1.243\end{array}$ & 94.358 \\
\hline \multicolumn{7}{|c|}{ Suhu Udara } \\
\hline \multirow{2}{*}{ Posisi } & \multirow{2}{*}{ Jum. Data } & \multirow{2}{*}{ Rerata } & \multirow{2}{*}{ Varian } & \multicolumn{2}{|c|}{ Koefisien Fourier } & \multirow{2}{*}{ Sum. Keragaman } \\
\hline & & & & $\mathbf{A j}$ & $\mathbf{B j}$ & \\
\hline 1. & 726.50 & 29.060 & 14.242 & $\begin{array}{r}1.400 \\
-0.926\end{array}$ & $\begin{array}{l}-5.015 \\
-0.062\end{array}$ & 98.187 \\
\hline 3. & 725.60 & 29.024 & 13.893 & $\begin{array}{c}1.444 \\
-0.939\end{array}$ & $\begin{array}{l}-4.933 \\
-0.084\end{array}$ & 98.274 \\
\hline 9. & 711.70 & 28.468 & 8.797 & $\begin{array}{c}2.015 \\
-0.656\end{array}$ & $\begin{array}{l}-3.578 \\
-0.339\end{array}$ & 98.915 \\
\hline
\end{tabular}

Penentuan fungsi Fourier berdasarkan persamaan 2 variabel kuat penerangan yakni mengacu pada total sumbangan keragaman $96.931 \%$ posisi 1 , $96.953 \%$ posisi 3 , dan $94.358 \%$ posisi 9 (Tabel 2) oleh masing-masing harmonik terhadap total keragaman data dari hubungan $\mathrm{s}_{\mathrm{m}}=\left(\mathrm{c}_{\mathrm{m}}{ }^{2} /(2 . \sigma)\right) * 100$ (prosedur penelitian point 3). Dimana $\sigma$ merupakan standar deviasi iklim mikro [15]. Fungsi Fourier variabel kuat penerangan tersusun atas data rerata, koefisien Fourier $(\boldsymbol{A} \boldsymbol{j}$ dan $\boldsymbol{B} \boldsymbol{j})$ dan banyaknya data harmonik, maka dapat ditulis untuk 3 posisi yang berbeda, sebagai berikut: 
Posisi 1:

$$
I(t)=32.869-26.145 \sin (2 \pi t) / 12-8.713 \cos (2 \pi t) / 12
$$

Posisi 3:

$$
I(t)=32.315-26.001 \sin (2 \pi t) / 12-8.748 \cos (2 \pi t) / 12-3.602 \sin (4 \pi t) / 12-0.723 \cos (4 \pi t) / 12
$$

Posisi 9:

$$
\begin{aligned}
I(t) & =13.823-11.660 \sin (2 \pi t) / 12-3.107 \cos (2 \pi t) / 12-1.862 \sin (4 \pi t) / 12-0.691 \cos (4 \pi t) / 12 \\
& -0.750 \cos (6 \pi t) / 12-1.243 \cos (6 \pi t) / 12
\end{aligned}
$$

Setelah diketahui fungsi Fourier untuk 3 posisi yang berbeda sepanjang transek pengukuran, maka luaran grafik kuat penerangan ditunjukan oleh Gambar 1:

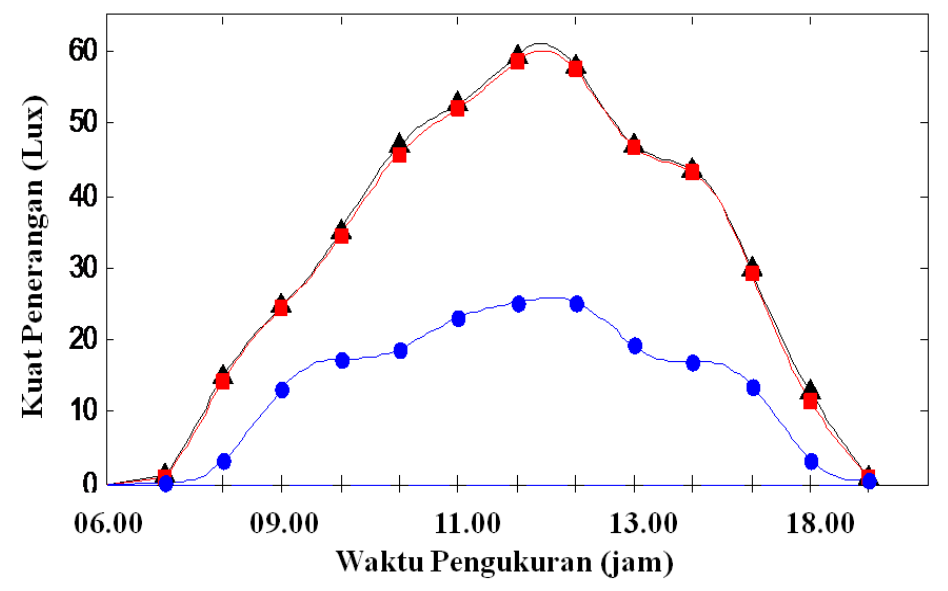

Gambar 1. Luaran grafik fungsi Fourier Kuat Penerangan, posisi-1 (warna hitam), posisi-3 (warna merah), dan posisi-9 (warna biru) yang mewakili 32 posisi sepanjang transek pengukuran.

Gambar 1, menampakan pola sinusoidal separuh perioda dari fluktuasi kuat penerangan dan pada malam hari kuat penerangan yakni bernilai nol. Grafik hitam dan merah menunjukan pola yang hampir sama. Karena tidak ada dan kurangnya kanopi untuk mereduksi panas matahari, sedangkan grafik biru terlihat lebih rendah, karena pada area 32 meter dinaungi oleh kanopi yang rapat. Secara fisis disebabkan oleh reduksi penetrasi cahaya matahari. Hasil penelitian ini sejalan dengan peneliti terdahulu yang melakukan pengukuran intensitas radiasi matahari sepanjang transek memotong batas hutan dengan lahan terbuka $[9,10,13,15]$.

Penyusunan fungsi Fourier berdasarkan persamaan 2 varibel suhu udara sama halnya dengan penentuan fungsi Fourier variabel kuat penerangan yang mana mengacu pada total sumbangan keragaman posisi 1 (98.187\%), posisi 3 (98.274\%), dan posisi 9 (98.915\%) (Tabel 2 rangkuman analisis suhu udara). Sehingga data untuk fungsi Fourier meliputi data rerata, koefisien Fourier $(\boldsymbol{A} \boldsymbol{j}$ dan $\boldsymbol{B} \boldsymbol{j})$ dan banyaknya data harmonik, maka dapat ditulis sebagai berikut:

Posisi 1:

$T(t)=29.060+1.400 \cos (2 \pi t) / 12-5.015 \sin (2 \pi t) / 12-0.926 \sin (4 \pi t) 12-0.062 \sin (4 \pi t) / 12$

Posisi 3:

$T(t)=29.024+1.444 \cos (2 \pi t) / 12-4.933 \sin (2 \pi t) / 12-0.939 \sin (4 \pi t) / 12-0.084 \sin (4 \pi t) / 12$

Posisi 9:

$T(t)=28.468+2.015 \cos (2 \pi t) / 12-3.578 \sin (2 \pi t) / 12-0.656 \cos (4 \pi t) / 12-0.339 \sin (4 \pi t) / 12$

Fungsi Fourier variabel suhu udara di 3 posisi yang berbeda, dapat dilukiskan seperti yang tunjukan oleh Gambar 2. 


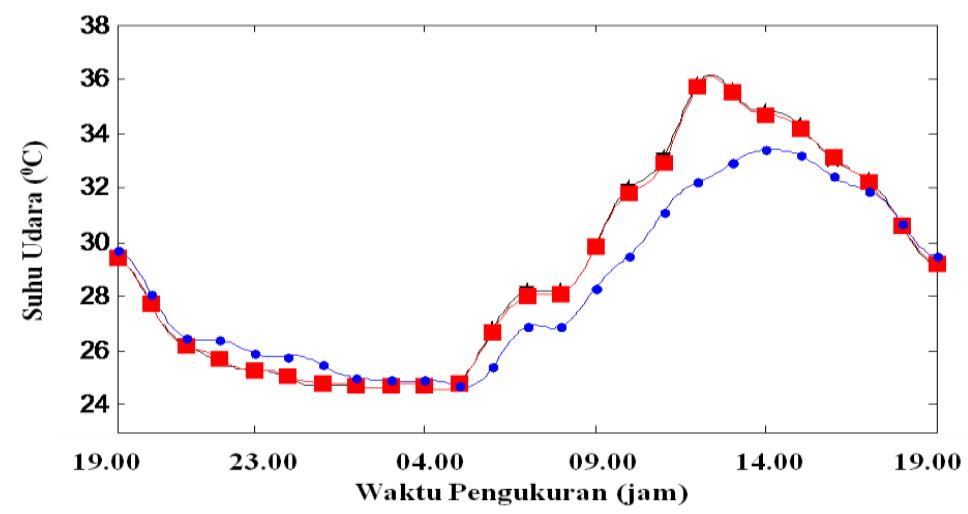

Gambar 2. Luaran grafik fungsi Fourier Suhu Udara, posisi-1 (warna hitam), posisi3 (warna merah), dan posisi-9 (warna biru) yang mewakili 32 posisi pada transek pengukuran.

Pola perubahan suhu udara menunjukan pola sinusoidal dengan perioda 24 jam (Gambar 2)., data yang ditampilkan oleh grafik suhu udara yakni waktu pengukuran 19.00 Waktu Indonesia Bagian Tengah (WITA) sampai ke waktu yang sama keesokan harinya. Pola dari ketiga grafik suhu udara memamerkan kesamaan penurunan suhu dari pukul 19.00 sampai 04.00. Memasuki pukul 05.00-19.00 mengisyaratkan kenaikan suhu udara, tapi posisi 9 lebih rendah, karena partikel-partikel udara dan tanah yang dipanasi oleh intensitas matahari mampu diredam oleh hutan bakau sehingga area 32 meter relatif stabil untuk suhu udara.

\subsection{Respon Suhu Udara Terhadap Kuat Penerangan}

Pemodelan, korelasi dan timelag suhu udara terhadap kuat penerangan yakni dengan menganalisis 32 posisi dalam transek. Sehingga menghasilkan koefisien korelasi maksimum (Gambar 3), terjadi saat fungsi kuat penerangan digeser mundur sejauh $t=d$.

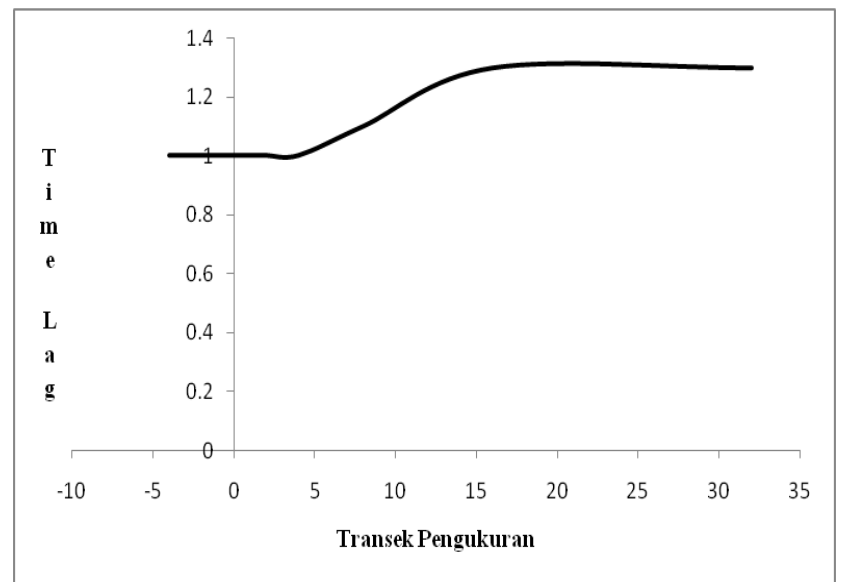

Gambar 3. Time lag perubahan kuat penerang terhadap suhu udara.

Timelag pada transek pengukuran berbatasan dengan laut, posisi-4 $\mathrm{m}$ (meter) dan $2 \mathrm{~m}$ di luar dan tepi bakau yakni 1.0 jam, sedangkan posisi-32 m 1.3 jam. Perubahan timelag dari setiap posisi pengukuran dipengaruhi oleh jarak antar posisi, menyebabkan difusi udara dengan suhu udara berbeda antara lingkungan dan ekosistem bakau. Saat kanopi bakau cukup rapat difusi termal arah vertikal relatif rendah, sehingga perubahan energi dalam bakau dikendalikan oleh difusi arah horizontal. 


\section{KESIMPULAN}

Pemodelan salah satu parameter iklim mikro yakni suhu udara sangat dipengaruhi oleh intesitas cahaya matahari. Suhu udara dari tiga posisi yang berbeda dalam satu transek pengukuran, mengungkapkan dengan jelas bahwa profil harian suhu udara memiliki perbedaan ekosistem hutan bakau. Analisis timelag suhu udara menunjukan ketaksamaan setiap posisi, sehingga dapat digunakan sebagai parameter untuk pemantauan suatu kondisis ekosistem bakau maupun yang lain. Dan mampu memperlihatkan proses difusi termal dari lingkungan ke dalam hutan bakau.

\section{DAFTAR PUSTAKA}

[1]. A. Mitra, "Sensitivity of Mangrove Ecosystem to Changing Climate", India : Springer, 2013.

[2]. C. D. Field, "Impacts of Expected Climate Change on Mangroves," Hydrobiologia, Vol. 295, No. 75-81, 1995.

[3]. C. S. Medellu, D. Tulandi, "Parameter: The Area of Microclimate Gradient Diurnal Dynamic for Characterization and Monitoring of Forest Ecosystem and Environment," International Journal of Environment Agriculture and Biotechnology, Vol. 3, No. 934-943, 2018.

[4]. C. S. Medellu, "The Area and Index of Diurnal Dynamic of Microclimate Gradient as a Mangrove-Environment Interaction Parameter," Journal of Natural Sciences Research, Vol. 3, No.14, 2013.

[5]. G. S. Campbell, "An Introduction to Environmental Biophysics", New York: Springer-Verlag, 1977.

[6]. H. Dym, H. P. McKean, "Fourier Series and Integrals", New York: Academic Press, Inc, 1972.

[7]. J. T. Houghton, Y. Ding, D. J. Griggs, M. Noguer, P. J. van der Linden, X. Dai, K. Maskell, \& C. A. Johnson, "Climate Change 2001: The Scientific Basis: Contribution of Working Group I to the Third Assessment Report of the Intergovernmental Panel on Climate Change", United Kingdom : Cambridge University Press, 2001.

[8]. J. Chen, S. C. Saunders, T. R. Crow, R. J. Naiman, K. D. Brosofske, G. D. Mroz, B. L. Brookshire, J. F. Franklin, "Microclimate in Forest Ecosystem and Landscape Ecology (Variationsin local climate can be used to monitor and compare the effects of different management regimes)," BioScience, Vol. 49, No. 4, 1999).

[9]. K. J. Hennenberga, D. Goetzea, J. Szarzynskib, B. Orthmann, B. Reinekingc, I. Steinke, S. Porembski, "Detection of Seasonal Variability in Microclimatic Borders and Ecotones Between Forest and Savanna", Basic and Applied Ecology, vol. 9, no. 275-285, 2008.

[10]. L. P. de Siqueira, M. B. de Matos, D. M. S. Matos, R. de Cássia Q. Portela, M. I. G. Braz, L. Silva-Lima, "Using the variances of Microclimate Variables to Determine Edge Effects in Small Atlantik Rain Forest Fragments, South-Eastern Brazil," Ecotropica, Vol. 10, No. 59-64, 2004.

[11]. M. R. Spiegel, "Fourier Analisis", New York: McGraw-Hill, Inc, 1974.

[12]. P. Bloomfield, "Fourier Analysis of Time Series: An Introduction", New York: John Wiley \& Sons, Inc. 2000.

[13]. R. J. Davies-Colley1, G. W. Payne1 and M. van Elswijk, "Microclimate Gradients Across a Forest Edge", New Zealand Journal of Ecology, Vol. 24, No. 2, 2000.

[14]. R. N. Palilingan, M. M. Pungus, "Aplikasi Analisis Fourier Dalam Fisika Lingkungan", Kosentrasi Fisika Lingkungan Jurusan Fisika FMIPA UNIMA, 2010

[15]. S. R. R. Pinto, G. Mendes, A. M. M. Santos, M. Dantas, M. Tabarelli, F. P. L. Melo1, "Landscape Attributes Drive Complex Spatial Microclimate Configuration of Brazilian Atlantic Forest Fragments," Tropical Conservation Science, Vol. 3, No. 4, 2010.

[16]. T. R. Oke, "Boundary Layer Climates", London: Methuen \& Co. Ltd, 1978.

[17]. V. Bewick, L. Cheek, \& J. Ball, "Statistics Review 7: Correlation and Regression," Critical Care, Vol. 7, No. 6, 2003.

[18]. Y. R. Noor, M. Khazali, \& I N. N. Suryadiputra, "Panduan Pengenalan Mangrove di Indonesia", Bogor: PHKA/WI-IP, 2006. 
